\title{
Effect of one-coordinated atoms on the electronic and optical properties of $\mathrm{ZnSe}$ clusters
}

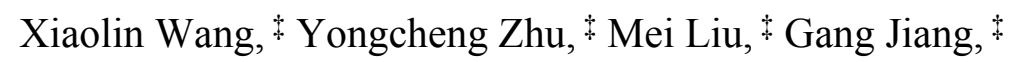 \\ Gao-Lei Hou, ${ }^{*} \uparrow$ Meng Zhang, ${ }^{*, *}$ Kui $\mathrm{Yu}^{*, \star,}$, , II \\ Institute of Atomic and Molecular Physics, Sichuan University, \\ Chengdu, 610065 Sichuan, P. R. China \\ †uantum Solid-State Physics, Department of Physics and Astronomy, KU \\ Leuven, Celestijnenlaan 200D, 3001 Leuven, Belgium \\ §Engineering Research Center in Biomaterials, Sichuan University, \\ Chengdu, 610065 Sichuan, P. R. China \\ IIState Key Laboratory of Polymer Materials Engineering, \\ Sichuan University, Chengdu, 610065 Sichuan, P. R. China \\ G. H. (email: gaolei.hou@kuleuven.be), M. Z. (email: mengzhang@scu.edu.cn), \\ K.Y. (email: kuiyu@scu.edu.cn)
}




\section{Table of contents}

$\begin{array}{ll}\text { Figure S1. The structures of } \mathrm{Zn}_{37} \mathrm{Se}_{20} . & \mathrm{S} 3\end{array}$

$\begin{array}{ll}\text { Figure S2. Optimized structure of } \mathrm{Zn}_{37} \mathrm{Se}_{20} \mathrm{H}_{68} . & \mathrm{S} 4\end{array}$

Figure S3. ELF pattern of $\mathrm{Zn}_{37} \mathrm{Se}_{20} \mathrm{H}_{68}$ cluster. $\quad$ S5

Figure S4. CDD pattern of $\mathrm{Zn}_{37} \mathrm{Se}_{20} \mathrm{H}_{68}$ cluster.

Figure S5. Optimized structures of $\mathrm{Zn}_{37-n} \mathrm{Se}_{20}(n=9-16)$ clusters. $\quad \mathrm{S} 7$

Figure S6. Optimized structures of $\mathrm{Zn}_{37} \mathrm{Se}_{20+m}(m=9-16)$ clusters. $\quad$ S8

Figure S7. PDOS of $\mathrm{Zn}_{37-n} \mathrm{Se}_{20}(n=2-4)$ clusters. $\quad \mathrm{S} 9$

Figure S8. PDOS of $\mathrm{Zn}_{37-n} \mathrm{Se}_{20}(n=5-7)$ clusters. $\quad \mathrm{S} 10$

Figure S9. PDOS of $\mathrm{Zn}_{37-n} \mathrm{Se}_{20}(n=8-10)$ clusters. $\quad \mathrm{S} 11$

$\begin{array}{ll}\text { Figure S10.PDOS of } \mathrm{Zn}_{37-n} \mathrm{Se}_{20}(n=11-13) \text { clusters. } & \mathrm{S} 12\end{array}$

$\begin{array}{ll}\text { Figure S11. PDOS of } \mathrm{Zn}_{37-n} \mathrm{Se}_{20}(n=14-16) \text { clusters. } & \mathrm{S} 13\end{array}$

Figure S12. PDOS of $\mathrm{Zn}_{37} \mathrm{Se}_{20+m}(m=2-4)$ clusters. $\quad \mathrm{S} 14$

Figure S13. PDOS of $\mathrm{Zn}_{37} \mathrm{Se}_{20+m}(m=5-7)$ clusters. $\quad \mathrm{S} 15$

Figure S14. PDOS of $\mathrm{Zn}_{37} \mathrm{Se}_{20+m}(m=8-10)$ clusters. $\quad \mathrm{S} 16$

$\begin{array}{ll}\text { Figure S15. PDOS of } \mathrm{Zn}_{37} \mathrm{Se}_{20+m}(m=11-13) \text { clusters. } & \mathrm{S} 17\end{array}$

$\begin{array}{ll}\text { Figure S16. PDOS of } \mathrm{Zn}_{37} \mathrm{Se}_{20+m}(m=14-16) \text { clusters. } & \mathrm{S} 18\end{array}$

Figure S17. Absorption spectra of $\mathrm{Zn}_{37} \mathrm{Se}_{20} \mathrm{H}_{68}$ and $\mathrm{ZnSe}$ MSC-299. $\quad$ S19

Table S1. Bader Charger of $\mathrm{Zn}_{37} \mathrm{Se}_{20} \mathrm{H}_{68} . \quad$ S20

Table S2. Average bond lengths of $\mathrm{Zn}_{37-n} \mathrm{Se}_{20}(n=0-16)$ and $\mathrm{Zn}_{37} \mathrm{Se}_{20+m}(m=1-$ 16) clusters. 


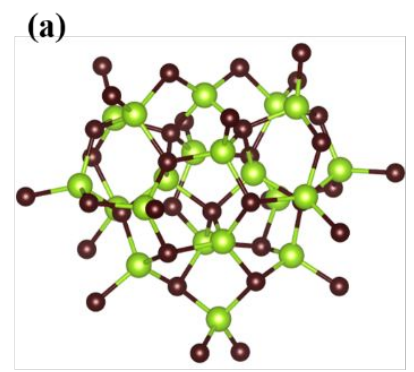

(b)

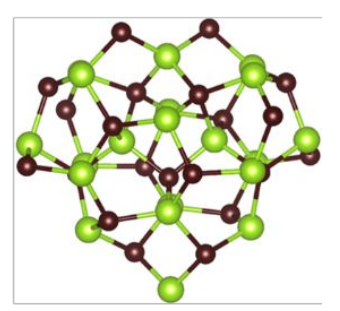

(c)<smiles>C1OOOOO1</smiles>

Figure S1. The structures of $\mathrm{Zn}_{37} \mathrm{Se}_{20}$ cluster (a), $\mathrm{Zn}_{37} \mathrm{Se}_{20}$ core after removing all the onecoordinated $\mathrm{Zn}$ atoms (b), and the six-membered ring (c). The different colors in the model represent Se (green) and $\mathrm{Zn}$ (brown) atoms. 

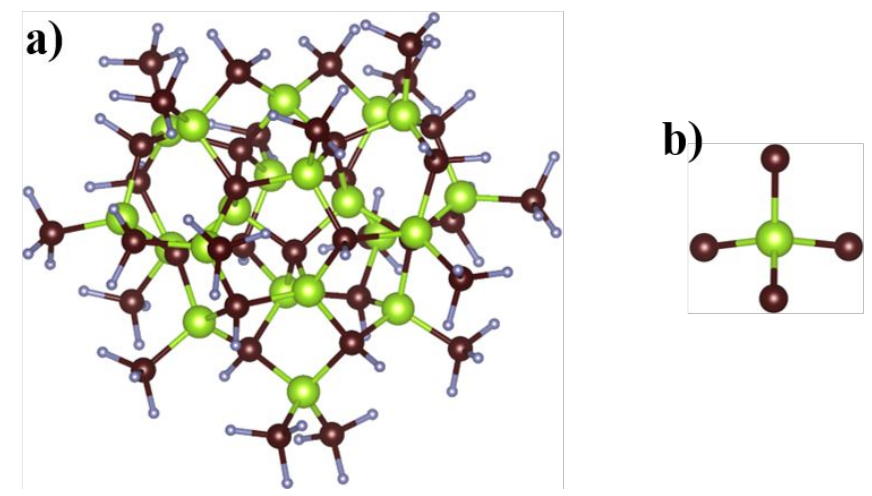

c)

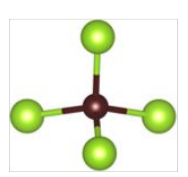

e)

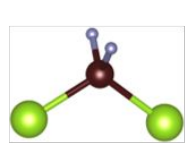

d)

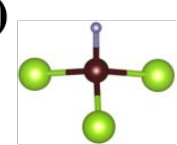

f)

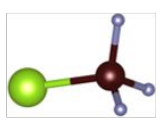

Figure S2. The optimized structure of $\mathrm{Zn}_{37} \mathrm{Se}_{20} \mathrm{H}_{68}$ (a), and the structures of four-coordinated Se atom bound with four Zn atoms (b), along with the four- (c), three- (d), two- (e) and onecoordinated $\mathrm{Zn}$ atoms (f). The different colors in the model represent $\mathrm{H}$ (silver), Se (green), and $\mathrm{Zn}$ (brown) atoms. 


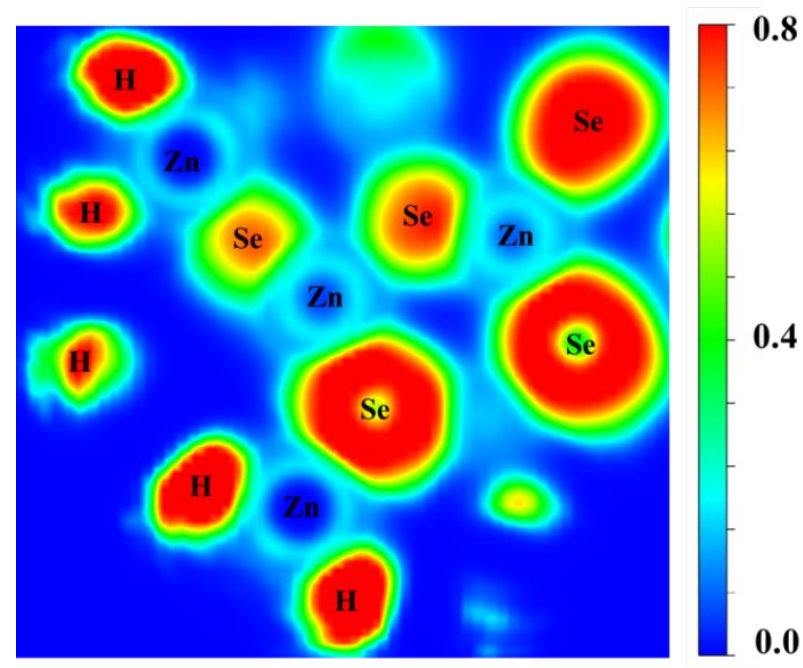

Figure S3. Electron localization function (ELF) pattern of $\mathrm{Zn}_{37} \mathrm{Se}_{20} \mathrm{H}_{68}$ cluster for the (101) plane. 


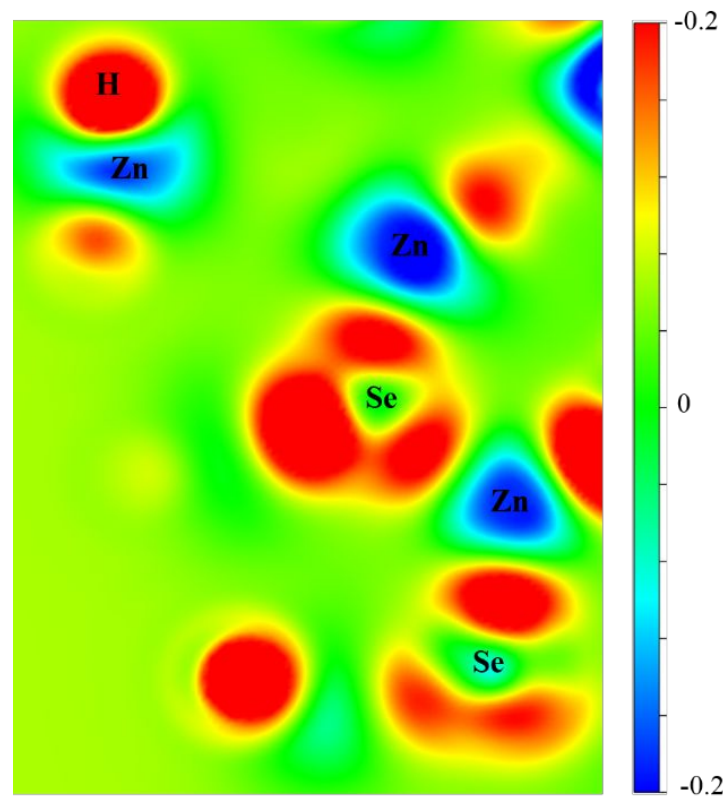

Figure S4. Charge density difference (CDD) pattern of $\mathrm{Zn}_{37} \mathrm{Se}_{20} \mathrm{H}_{68}$ cluster for the (112) plane. 

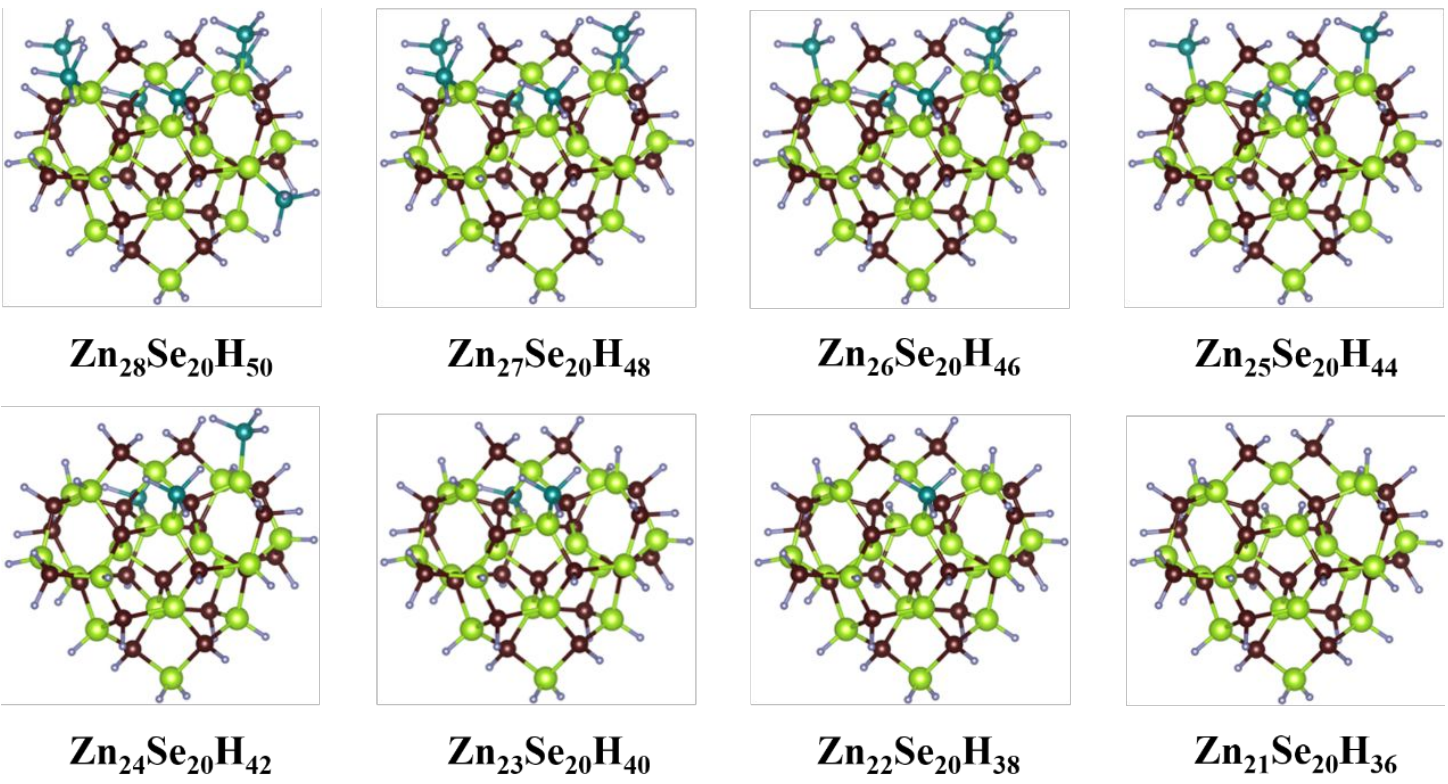

Figure S5. Optimized structures of $\mathrm{Zn}_{37-n} \mathrm{Se}_{20}(n=9-16)$ clusters with the dangling bonds saturated by pseudo hydrogens. The different colors in the model represent $\mathrm{H}$ (silver), Se (green), and Zn atoms in either one-coordinated state (cyan) or other coordinated states (brown). 

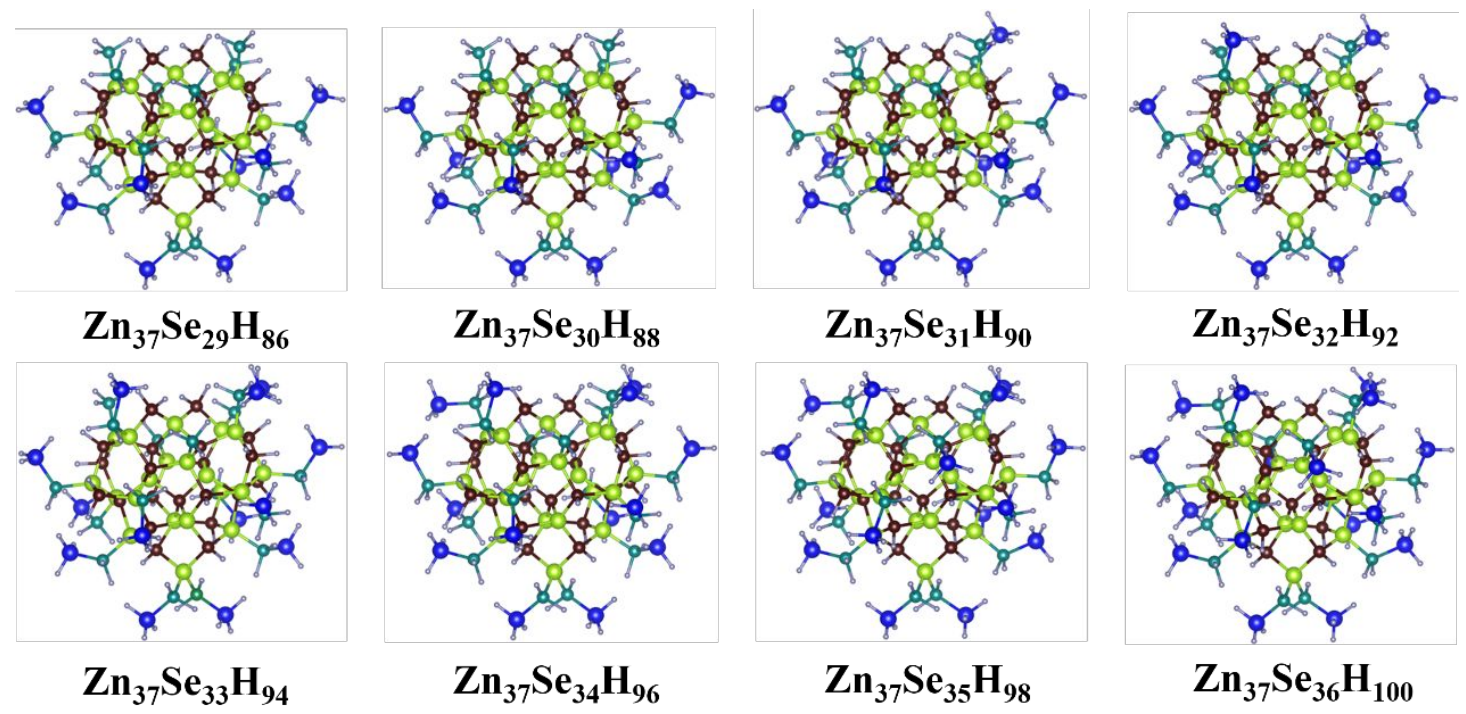

Figure S6. Optimized structures of $\mathrm{Zn}_{37} \mathrm{Se}_{20+m}(m=9-16)$ clusters with the dangling bonds saturated by pseudo hydrogens. The different colors in the model represent $\mathrm{H}$ (silver), $\mathrm{Se}$ atoms in four- (green) or one-coordinated states (blue), and $\mathrm{Zn}$ atoms in either onecoordinated state (cyan) or other coordinated states (brown). 

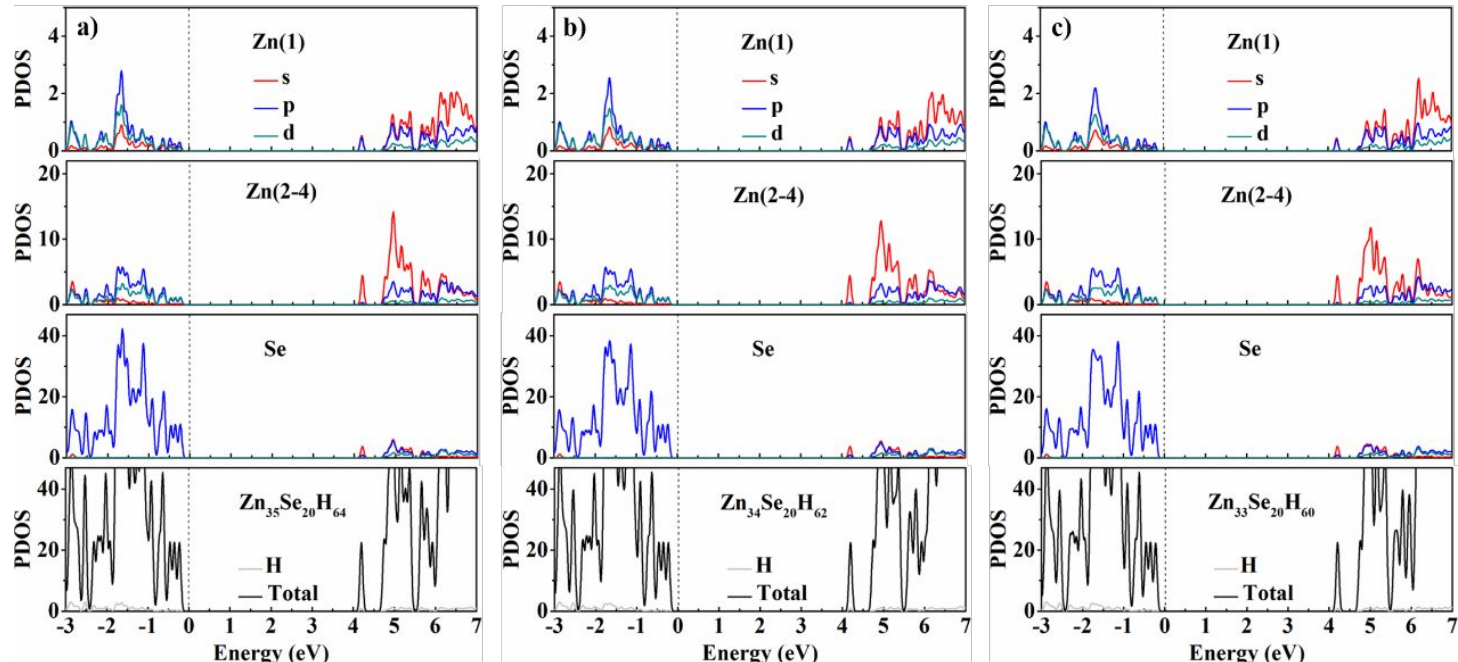

Figure S7. PDOS of $\mathrm{Zn}_{35} \mathrm{Se}_{20} \mathrm{H}_{64}$ (a), $\mathrm{Zn}_{34} \mathrm{Se}_{20} \mathrm{H}_{62}$ (b), and $\mathrm{Zn}_{33} \mathrm{Se}_{20} \mathrm{H}_{60}$ (c). Fermi energy is set to zero. 

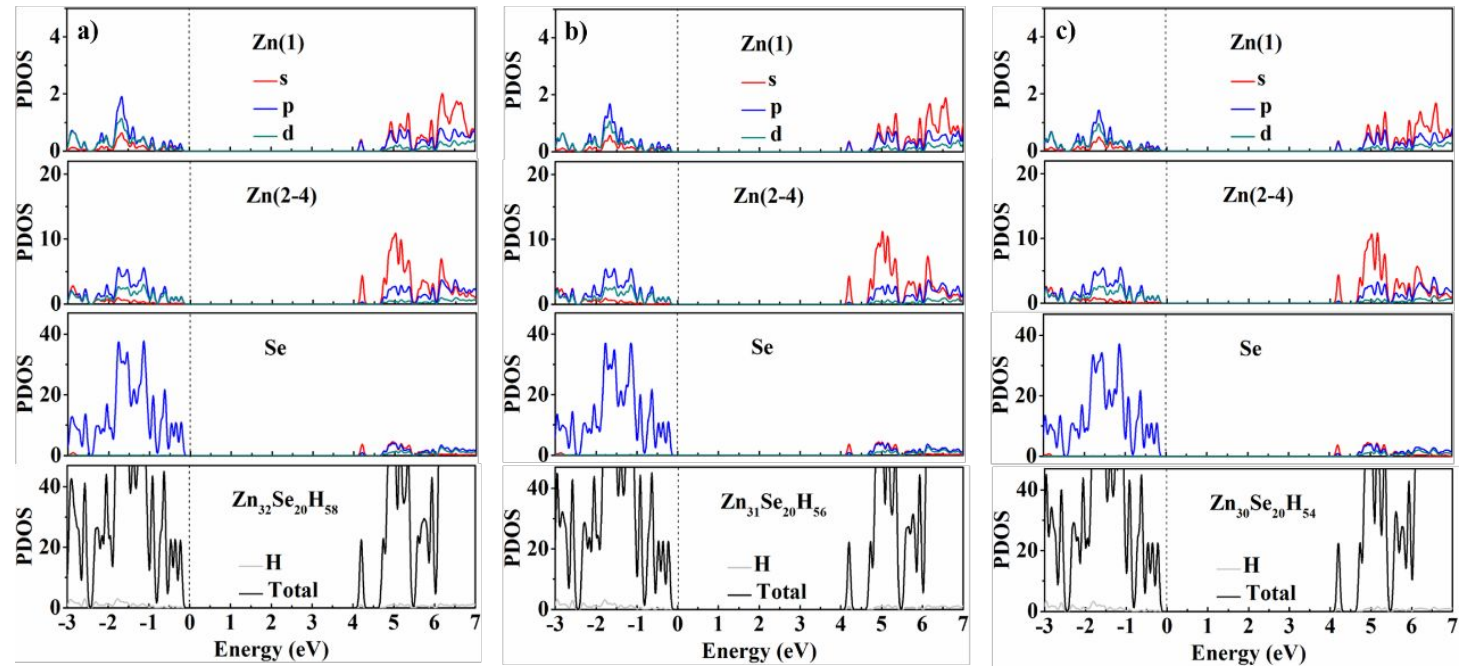

Figure S8. PDOS of $\mathrm{Zn}_{32} \mathrm{Se}_{20} \mathrm{H}_{58}$ (a), $\mathrm{Zn}_{31} \mathrm{Se}_{20} \mathrm{H}_{56}$ (b), and $\mathrm{Zn}_{30} \mathrm{Se}_{20} \mathrm{H}_{54}$ (c). Fermi energy is set to zero. 

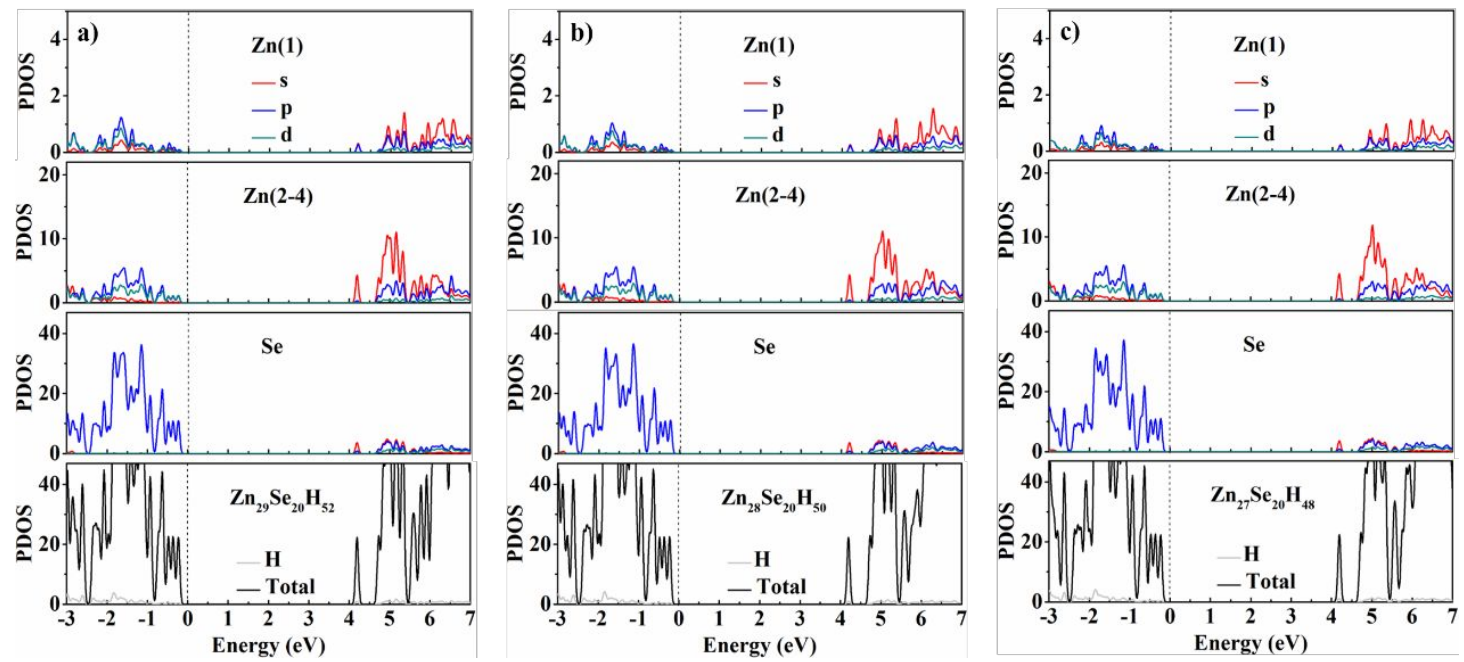

Figure S9. PDOS of $\mathrm{Zn}_{29} \mathrm{Se}_{20} \mathrm{H}_{52}$ (a), $\mathrm{Zn}_{28} \mathrm{Se}_{20} \mathrm{H}_{50}$ (b), and $\mathrm{Zn}_{27} \mathrm{Se}_{20} \mathrm{H}_{48}$ (c). Fermi energy is set to zero. 

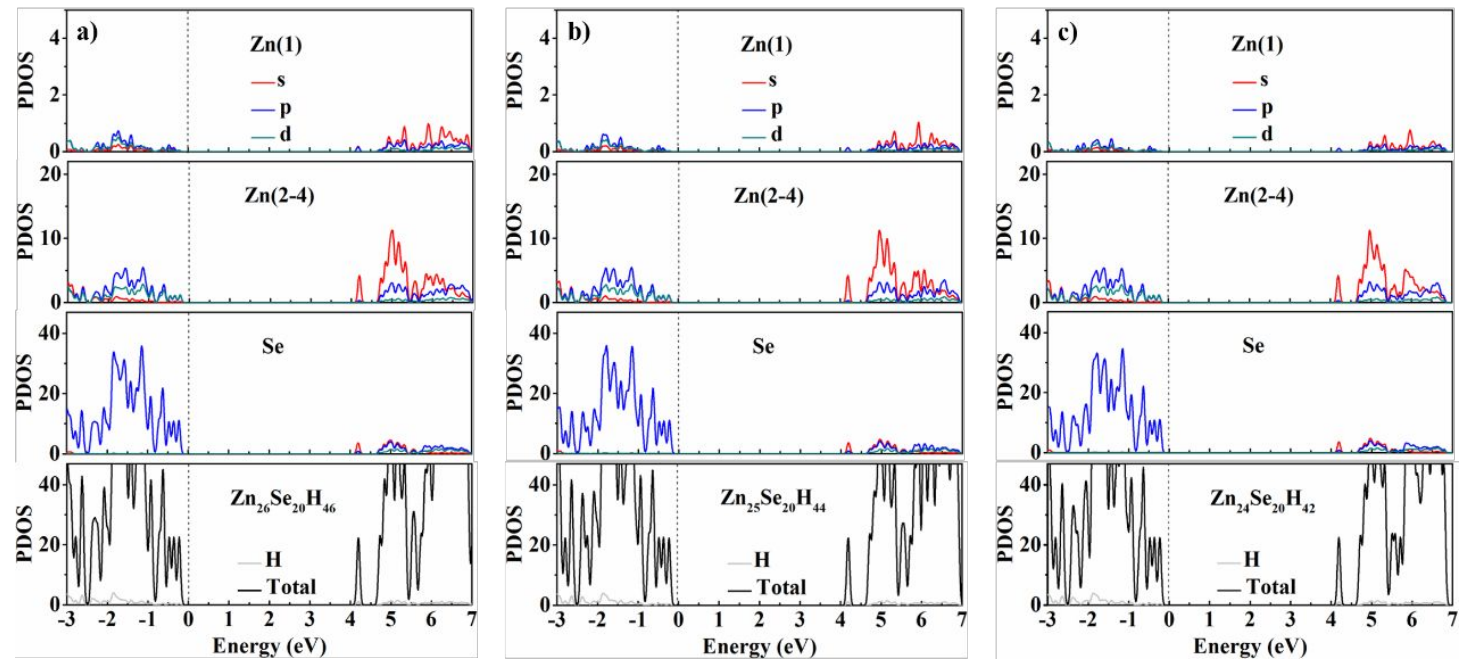

Figure S10. PDOS of $\mathrm{Zn}_{26} \mathrm{Se}_{20} \mathrm{H}_{46}$ (a), $\mathrm{Zn}_{25} \mathrm{Se}_{20} \mathrm{H}_{44}$ (b), and $\mathrm{Zn}_{24} \mathrm{Se}_{20} \mathrm{H}_{42}$ (c). Fermi energy is set to zero. 

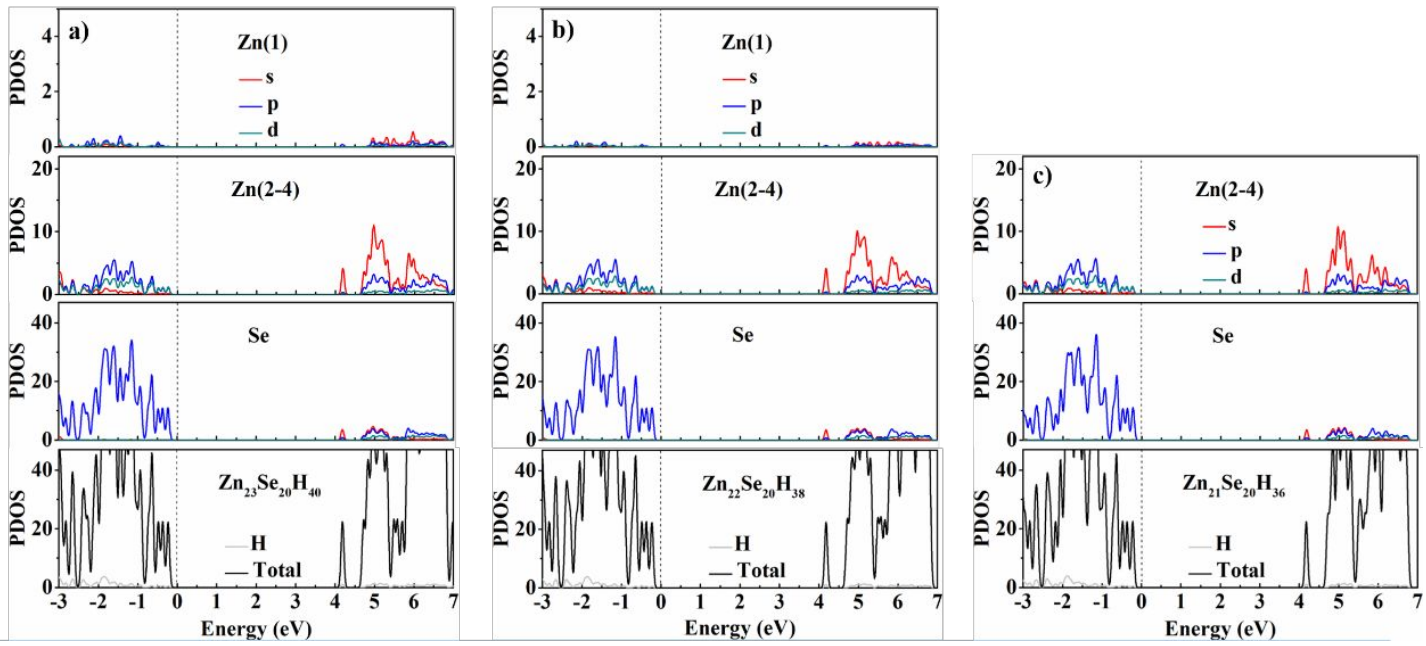

Figure S11. PDOS of $\mathrm{Zn}_{23} \mathrm{Se}_{20} \mathrm{H}_{40}$ (a), $\mathrm{Zn}_{22} \mathrm{Se}_{20} \mathrm{H}_{38}$ (b), and $\mathrm{Zn}_{21} \mathrm{Se}_{20} \mathrm{H}_{36}$ (c). Fermi energy is set to zero. 

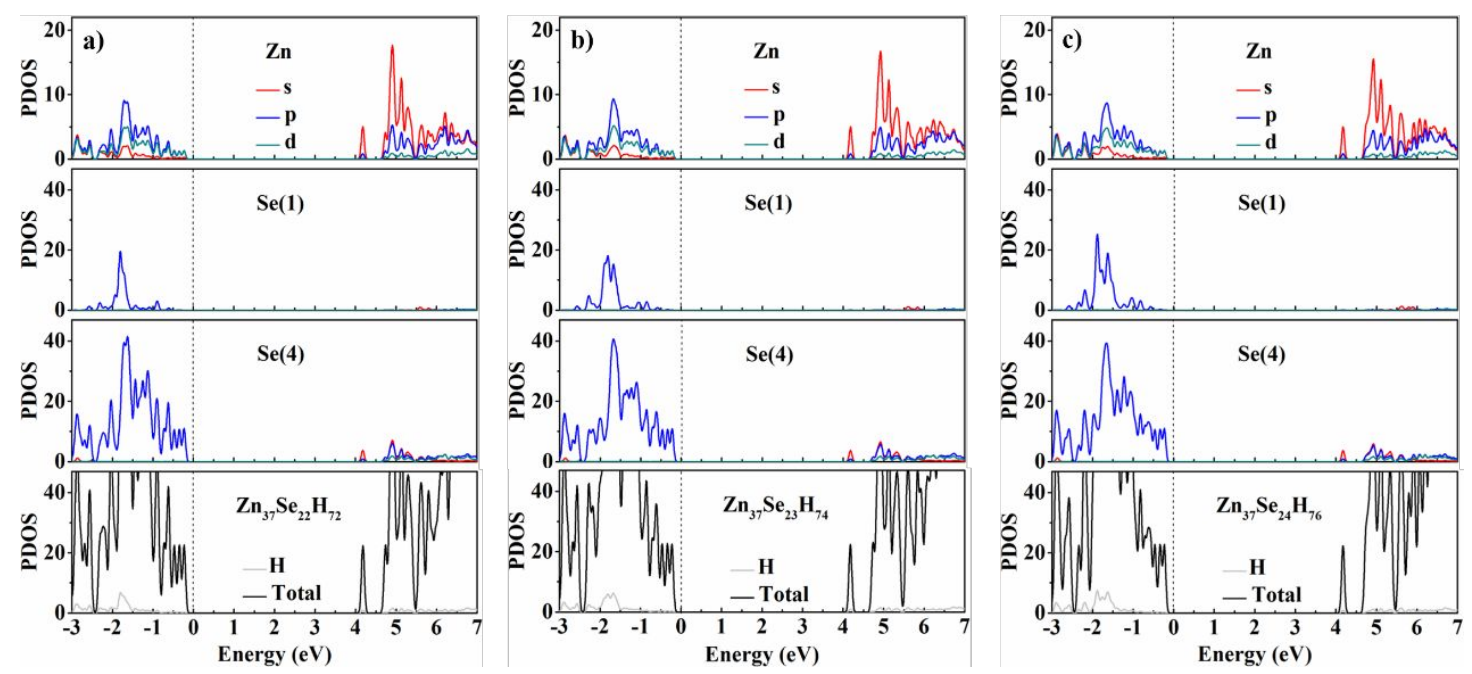

Figure S12. PDOS of $\mathrm{Zn}_{37} \mathrm{Se}_{22} \mathrm{H}_{72}$ (a), $\mathrm{Zn}_{37} \mathrm{Se}_{23} \mathrm{H}_{74}$ (b), and $\mathrm{Zn}_{37} \mathrm{Se}_{24} \mathrm{H}_{76}$ (c). Fermi energy is set to zero. 

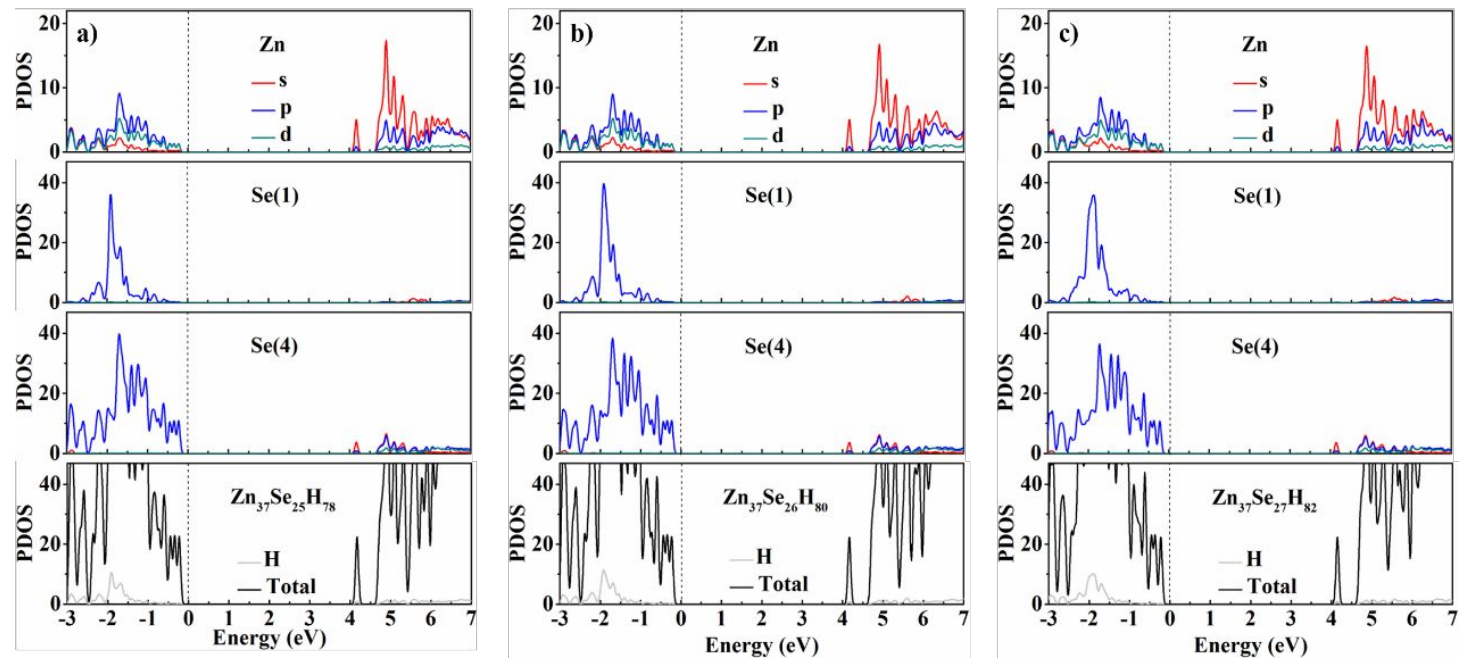

Figure S13. PDOS of $\mathrm{Zn}_{37} \mathrm{Se}_{25} \mathrm{H}_{78}$ (a), $\mathrm{Zn}_{37} \mathrm{Se}_{26} \mathrm{H}_{80}$ (b), and $\mathrm{Zn}_{37} \mathrm{Se}_{27} \mathrm{H}_{82}$ (c). Fermi energy is set to zero. 

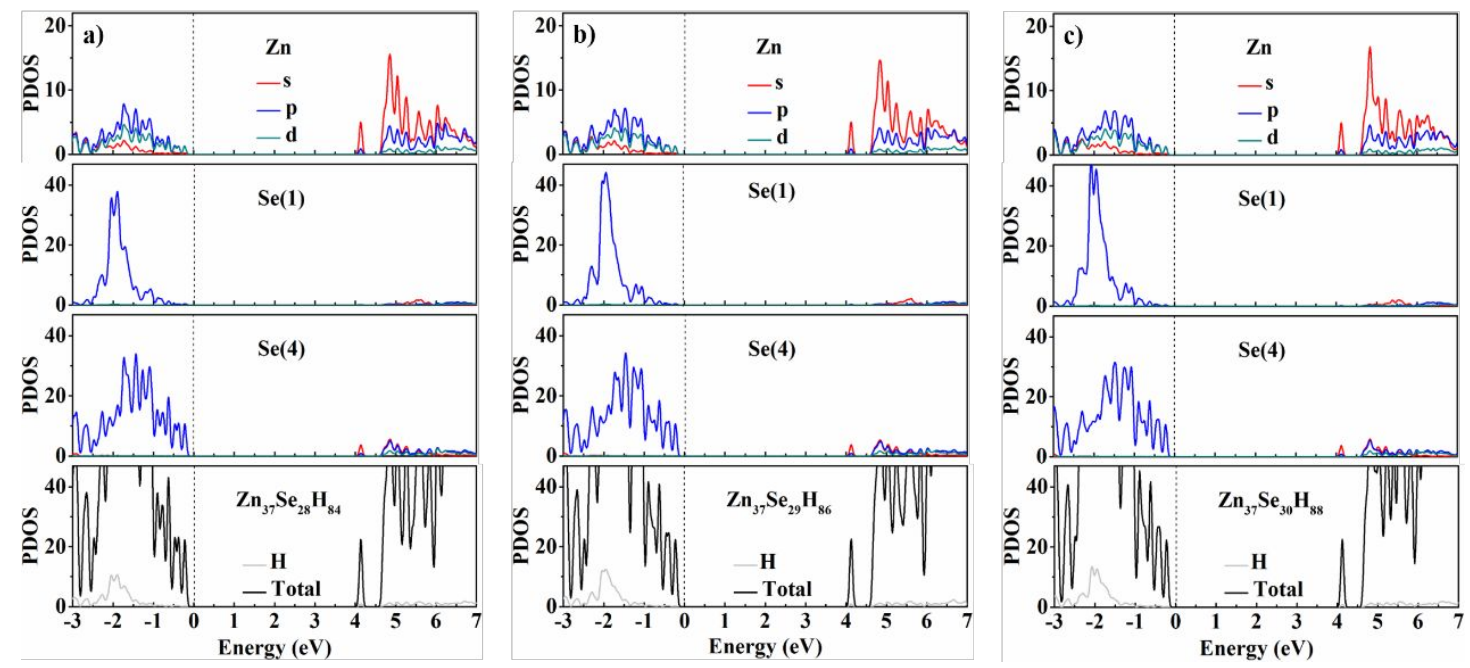

Figure S14. PDOS of $\mathrm{Zn}_{37} \mathrm{Se}_{28} \mathrm{H}_{84}$ (a), $\mathrm{Zn}_{37} \mathrm{Se}_{29} \mathrm{H}_{86}$ (b), and $\mathrm{Zn}_{37} \mathrm{Se}_{30} \mathrm{H}_{88}$ (c). Fermi energy is set to zero. 

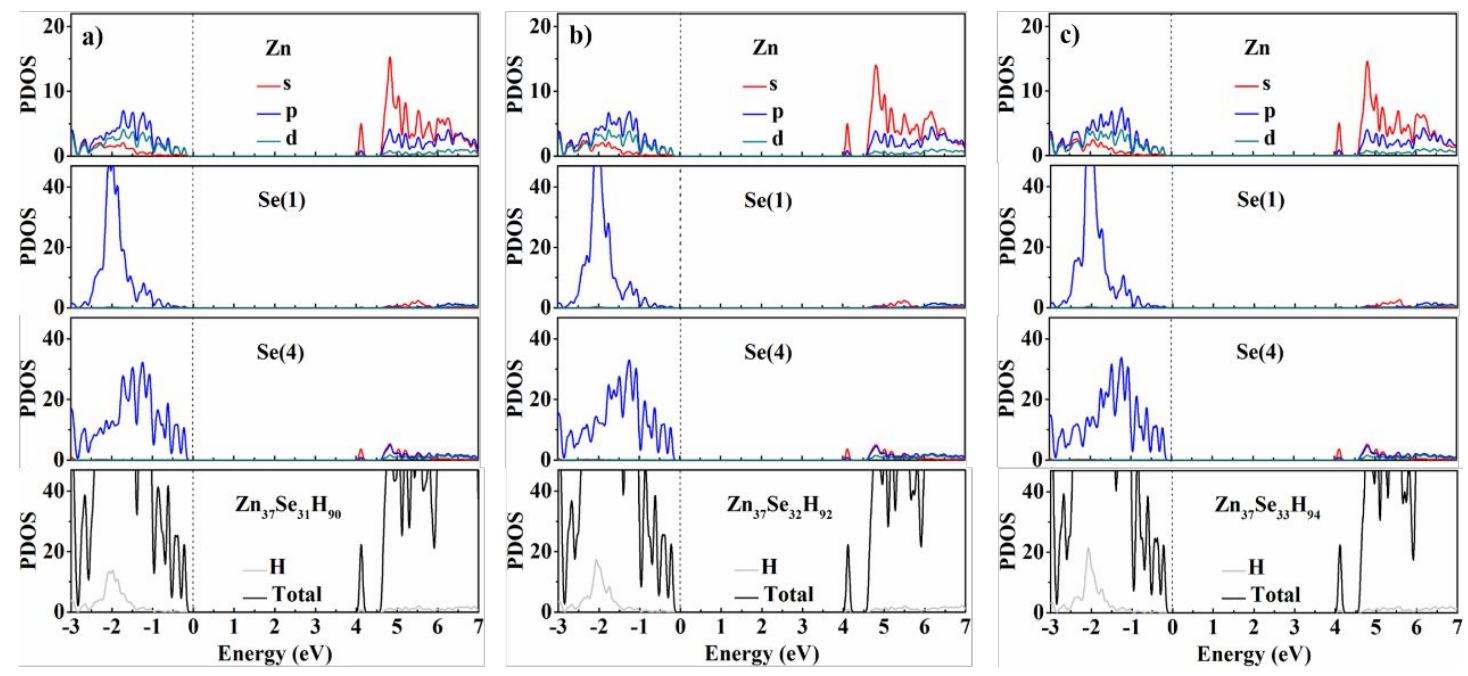

Figure S15. PDOS of $\mathrm{Zn}_{37} \mathrm{Se}_{31} \mathrm{H}_{90}$ (a), $\mathrm{Zn}_{37} \mathrm{Se}_{32} \mathrm{H}_{92}$ (b), and $\mathrm{Zn}_{37} \mathrm{Se}_{33} \mathrm{H}_{94}$ (c). Fermi energy is set to zero. 

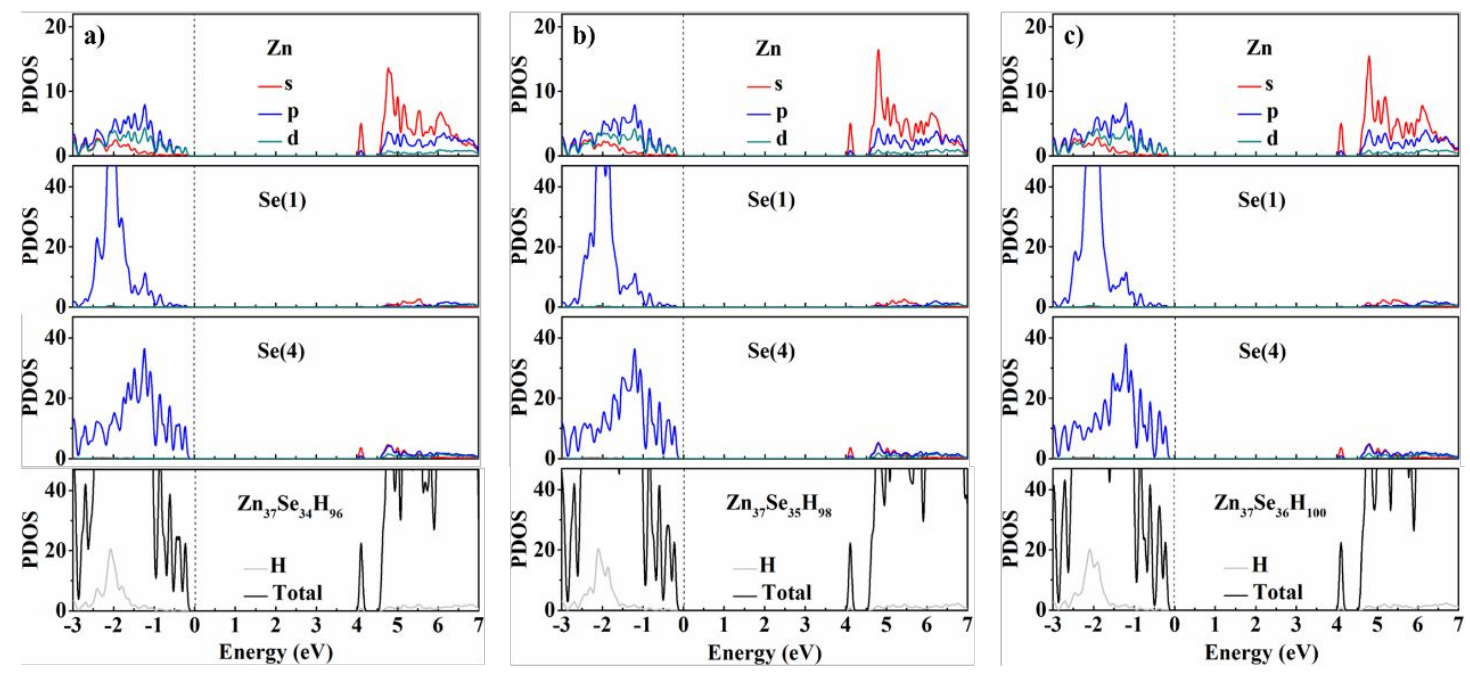

Figure S16. PDOS of $\mathrm{Zn}_{37} \mathrm{Se}_{34} \mathrm{H}_{96}$ (a), $\mathrm{Zn}_{37} \mathrm{Se}_{35} \mathrm{H}_{98}$ (b), and $\mathrm{Zn}_{37} \mathrm{Se}_{36} \mathrm{H}_{100}$ (c). Fermi energy is set to zero. 


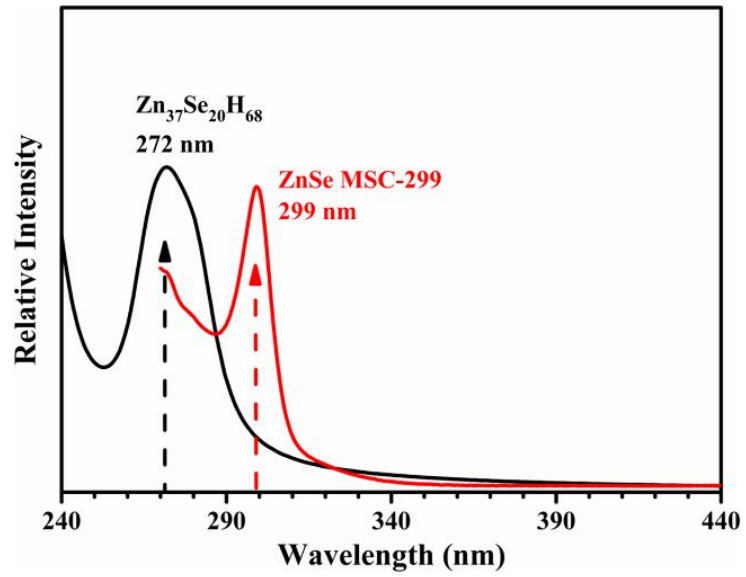

Figure S17. Absorption spectra obtained from the calculation of $\mathrm{Zn}_{37} \mathrm{Se}_{20} \mathrm{H}_{68}$ cluster (black) and experimental measurement of ZnSe MSC-299 (red). ${ }^{1}$ Adapted with permission from Ref 1. Copyright [2018] John Wiley and Sons. 
Table S1. Bader Charger of $\mathrm{Zn}_{37} \mathrm{Se}_{20} \mathrm{H}_{68}$ cluster. $\Delta Q$ is the total charge transfer of atoms and $\Delta \bar{Q}$ is the average charge transfer of each atom.

\begin{tabular}{cccc}
\hline Atom & Amounts & $\Delta Q\left(\mathrm{e}^{\mathrm{e}}\right)$ & $\Delta \bar{Q}\left(\mathrm{e}^{-}\right)$ \\
\hline One-coordinated $\mathrm{Zn}$ & 16 & -18.77 & -1.17 \\
Two-coordinated $\mathrm{Zn}$ & 6 & -6.40 & -1.07 \\
Three-coordinated Zn & 8 & -7.76 & -0.97 \\
Four-coordinated Zn & 7 & -5.92 & -0.85 \\
$\mathrm{Se}$ & 20 & 17.15 & 0.86 \\
$\mathrm{H}$ & 68 & 19.53 & 0.29 \\
\hline
\end{tabular}


Table S2. The average bond lengths of Se(2)-Zn and $\mathrm{Se}(4)-\mathrm{Zn}$ in $\mathrm{Zn}_{37-\mathrm{n}} \mathrm{Se}_{20}(n=0-16)$ and $\mathrm{Se}(4)-\mathrm{Zn}$ in $\mathrm{Zn}_{37} \mathrm{Se}_{20+m}(m=1-16)$ clusters.

\begin{tabular}{ccccc}
\hline Clusters & $\begin{array}{c}\text { Average } \mathrm{Se} \\
(2)-\mathrm{Zn} \text { bond } \\
\text { length }(\AA)\end{array}$ & $\begin{array}{c}\text { Average } \mathrm{Se} \\
(4)-\mathrm{Zn} \text { bond } \\
\text { length }(\AA)\end{array}$ & Clusters & $\begin{array}{c}\text { Average } \mathrm{Se} \\
(4)-\mathrm{Zn} \text { bond } \\
\text { length }(\AA)\end{array}$ \\
\hline $\mathrm{Zn}_{37} \mathrm{Se}_{20} \mathrm{H}_{68}$ & -- & -- & & \\
$\mathrm{Zn}_{36} \mathrm{Se}_{20} \mathrm{H}_{66}$ & -- & 2.475 & $\mathrm{Zn}_{37} \mathrm{Se}_{21} \mathrm{H}_{70}$ & 2.474 \\
$\mathrm{Zn}_{35} \mathrm{Se}_{20} \mathrm{H}_{64}$ & 2.447 & 2.474 & $\mathrm{Zn}_{37} \mathrm{Se}_{22} \mathrm{H}_{72}$ & 2.474 \\
$\mathrm{Zn}_{34} \mathrm{Se}_{20} \mathrm{H}_{62}$ & 2.450 & 2.474 & $\mathrm{Zn}_{37} \mathrm{Se}_{23} \mathrm{H}_{74}$ & 2.470 \\
$\mathrm{Zn}_{33} \mathrm{Se}_{20} \mathrm{H}_{60}$ & 2.452 & 2.473 & $\mathrm{Zn}_{37} \mathrm{Se}_{24} \mathrm{H}_{76}$ & 2.475 \\
$\mathrm{Zn}_{32} \mathrm{Se}_{20} \mathrm{H}_{58}$ & 2.453 & 2.471 & $\mathrm{Zn}_{37} \mathrm{Se}_{25} \mathrm{H}_{78}$ & 2.475 \\
$\mathrm{Zn}_{31} \mathrm{Se}_{20} \mathrm{H}_{56}$ & 2.453 & 2.474 & $\mathrm{Zn}_{37} \mathrm{Se}_{26} \mathrm{H}_{80}$ & 2.476 \\
$\mathrm{Zn}_{30} \mathrm{Se}_{20} \mathrm{H}_{54}$ & 2.454 & 2.473 & $\mathrm{Zn}_{37} \mathrm{Se}_{27} \mathrm{H}_{82}$ & 2.476 \\
$\mathrm{Zn}_{29} \mathrm{Se}_{20} \mathrm{H}_{52}$ & 2.454 & 2.475 & $\mathrm{Zn}_{37} \mathrm{Se}_{28} \mathrm{H}_{84}$ & 2.477 \\
$\mathrm{Zn}_{28} \mathrm{Se}_{20} \mathrm{H}_{50}$ & 2.455 & 2.475 & $\mathrm{Zn}_{37} \mathrm{Se}_{29} \mathrm{H}_{86}$ & 2.477 \\
$\mathrm{Zn}_{27} \mathrm{Se}_{20} \mathrm{H}_{48}$ & 2.455 & 2.475 & $\mathrm{Zn}_{37} \mathrm{Se}_{30} \mathrm{H}_{88}$ & 2.477 \\
$\mathrm{Zn}_{26} \mathrm{Se}_{20} \mathrm{H}_{46}$ & 2.455 & 2.475 & $\mathrm{Zn}_{37} \mathrm{Se}_{31} \mathrm{H}_{90}$ & 2.477 \\
$\mathrm{Zn}_{25} \mathrm{Se}_{20} \mathrm{H}_{44}$ & 2.457 & 2.475 & $\mathrm{Zn}_{37} \mathrm{Se}_{32} \mathrm{H}_{92}$ & 2.477 \\
$\mathrm{Zn}_{24} \mathrm{Se}_{20} \mathrm{H}_{42}$ & 2.456 & 2.475 & $\mathrm{Zn}_{37} \mathrm{Se}_{33} \mathrm{H}_{94}$ & 2.474 \\
$\mathrm{Zn}_{23} \mathrm{Se}_{20} \mathrm{H}_{40}$ & 2.457 & 2.476 & $\mathrm{Zn}_{37} \mathrm{Se}_{34} \mathrm{H}_{96}$ & 2.483 \\
$\mathrm{Zn}_{22} \mathrm{Se}_{20} \mathrm{H}_{38}$ & 2.457 & 2.476 & $\mathrm{Zn}_{37} \mathrm{Se}_{35} \mathrm{H}_{98}$ & 2.478 \\
$\mathrm{Zn}_{21} \mathrm{Se}_{20} \mathrm{H}_{36}$ & 2.458 & 2.476 & $\mathrm{Zn}_{37} \mathrm{Se}_{36} \mathrm{H}_{100}$ & 2.479 \\
\hline
\end{tabular}




\section{Supplementary reference}

1. Wang, L.; Hui, J.; Tang, J.; Rowell, N.; Zhang, B.; Zhu, T.; Zhang, M.; Hao, X.; Fan, H.; Zeng, J.; Han. S.; Yu, K. Precursor Self-Assembly Identified as a General Pathway for Colloidal Semiconductor Magic-Size Clusters. Adv. Sci. 2018, 5, 1800632. 